\title{
DÜBLIN
}

Technological University Dublin

ARROW@TU Dublin

Conference Papers

School of Physics \& Clinical \& Optometric

Science

2018

\section{Tissue Mimicking Materials for Multi-Modality Breast Phantoms}

\author{
G. Fiaschetti \\ Sapienza University of Rome \\ Jacinta Browne \\ Technological University Dublin, jacinta.browne@tudublin.ie \\ M. Cavagnaro \\ Sapienza University of Rome
}

See next page for additional authors

Follow this and additional works at: https://arrow.tudublin.ie/scschphycon

Part of the Physical Sciences and Mathematics Commons

\section{Recommended Citation}

G. Fiaschetti, J. E. Browne, M. Cavagnaro, L. Farina and G. Ruvio, "Tissue Mimicking Materials for MultiModality Breast Phantoms," 2018 2nd URSI Atlantic Radio Science Meeting (AT-RASC), 2018, pp. 1-6, doi: 10.23919/URSI-ATRASC.2018.8471644.

This Conference Paper is brought to you for free and open access by the School of Physics \& Clinical \& Optometric Science at ARROW@TU Dublin. It has been accepted for inclusion in Conference Papers by an authorized administrator of ARROW@TU Dublin. For more information, please contact arrow.admin@tudublin.ie, aisling.coyne@tudublin.ie, gerard.connolly@tudublin.ie. Funder: Horizon 2020; European Research Council

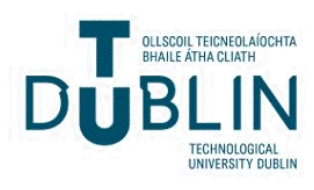




\section{Authors}

G. Fiaschetti, Jacinta Browne, M. Cavagnaro, L. Farina, and G. Ruvio 


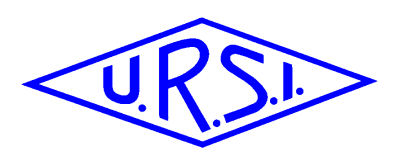

\title{
Tissue Mimicking Materials for Multi-modality Breast Phantoms
}

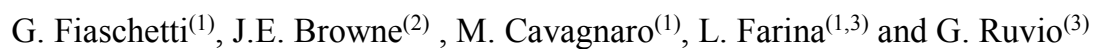 \\ (1) Dept. of Information Engineering, Electronics and Telecommunications, Sapienza University of Rome, Rome, Italy \\ (2) School of Physics, Dublin Institute of Technology, Dublin, Ireland \\ (3) Translational Medical Device Laboratory \& CURAM, National University of Ireland, Galway, Ireland
}

\begin{abstract}
The paper proposes two different Tissue Mimicking Material (TMM) techniques for the development of breast phantoms which are suitable for multi-modality imaging. In particular, the focus is on the behavior of dielectric and acoustic properties when fat, sodium chloride and sugar are added to the mixtures.
\end{abstract}

\section{Introduction}

Breast cancer is the most common cancer in women and the second cause of female cancer death, after lungs and bronchus cancer. One out of twelve women (8\%) in Europe and one out of eight (12\%) in the United Stated is likely to develop invasive breast cancer during their lifetime [1]. The American Cancer Society estimated 252,710 new cases of breast cancer in US women in 2017 [2].

Image-based diagnostics plays a fundamental role in early breast cancer detection. Besides common techniques (mammography, ultrasound, Magnetic Resonance Imaging, Computed Tomography), Microwave Imaging (MWI) has shown potential in identifying and characterizing breast lesions. Due to the fact that MWI is an emerging technique, anthropomorphic breast phantoms are required for testing and benchmarking different scanning setups and reconstruction algorithms. Breast phantoms represent a standard consistent patient with known clinical truth, which can be typically employed for different purposes. Phantoms are crucial in operator training for imaging or image-guided interventional procedures. They also represent a quality assessment tool for initial implementation of an imaging protocol and represent routine quality control of image modalities to ensure that the scanning system is operating properly during time. Phantoms can be a tool for optimization of scanning parameters. Most existing breast phantoms, either commercially available or presented in literature, are phantoms for mammography, ultrasound or MRI (e.g. CIRS Multi-Modality Breast Biopsy and Sonographic Trainer model 073, Yezitronix's Multi-Modality Breast Phantom). With the investigation of MWI as a novel technique for breast cancer detection, many physical anthropomorphic phantoms were developed in the past 15 years. One of the first phantoms was introduced by Li et al in 2003 [3]. With a cylindrical geometry, it reproduced fibroglandular tissue and tumour dielectric properties at 0.9
$\mathrm{GHz}$ using corn syrup and agar. The phantom was used for testing three model-based imaging systems. In 2005, Lazebnik et al. [4] introduced tissue mimicking materials that could be employed to construct heterogeneous breast phantoms. Kerosene and safflower oil-in-gelatine dispersions were proposed to simulate human tissues dielectric properties from $500 \mathrm{MHz}$ to $20 \mathrm{GHz}$. The obtained materials were solid, elastic, stable over a long period. However, formaldehyde, used as a cross-linker between oil and gelatin, implied a complex manufacture process because of toxicity of materials. Also in 2005, Sill et al. [5] developed a cylindrical phantom in which skin was simulated with a flexible silicon sheet loaded with dielectric fillers, fat with flour, canola oil and saline solution and the tumor with alginate powder, water and salt. This phantom was extremely rudimental and showed short-term stability, with minimal variations in dielectric properties over a 3-week period. A more realistically shaped breast phantom was developed by Winter et al. in 2008 [6] in order to evaluate an imaging algorithm. In this phantom, skin and fat were reproduced by an oil-ingelatine dispersion. Another breast phantom was developed by Klemm et al. in 2009 [7]. This was a hemispheric phantom to test a microwave radar-based imaging system in the frequency range between 3 and 10 GHz. Skin, adipose tissue, fibroglandular tissue and tumour were simulated with mixtures of TX-151, polythene powder and water in different percentages. In 2011, Mashal et al. [8] developed breast phantoms with four different breast densities: mostly fat, scattered fibroglandular, heterogeneously dense, extremely dense. Skin, adipose tissue, a heterogeneous mix and fibroglandular tissue were made with oil-in-gelatine dispersions by varying the percentage of oil. For each phantom, the volume percentages of adipose tissue, fibroglandular tissue and heterogeneous mix changed. The phantoms showed accurate dielectric properties in the frequency bandwidth $1-6 \mathrm{GHz}$ and long term stability. In 2012, Burfeindt et al. [9] introduced a realistic 3D-printed breast phantom for use in preclinical experimental microwave imaging studies. The phantom reproduced adipose and fibroglandular tissue. The adipose layer was simulated by plastic material which was $3 \mathrm{D}$ printed, while the fibroglandular tissue was simulated by liquid-filled voids in the plastic material. The 3D model for the phantom was MRI-derived from a human subject. Therefore, the phantom had high anatomical accuracy. Materials showed 
a good match with breast tissues dielectric properties in the frequency range between $500 \mathrm{MHz}$ and $3.5 \mathrm{GHz}$.

The aim of this work is the investigation of multimodal TMMs of breast tissues for MWI across the frequency bandwidth $0.5-4 \mathrm{GHz}$, B-mode ultrasound with the potential to stretch to mammography, MRI and CT applications. Multimodal TMMs need to mimic breast tissues in terms of physical, mechanical and dielectric characteristics. A further requirement is TMMs should be suitable for ergonomic, easily manufacturable and solid phantoms (in order to avoid housing containers for liquid materials).

\section{Recipes and Measurement Setup}

In this section the investigation of dielectric, acoustic and physical properties for different materials and mixtures are presented. Tables 1 and 2 show the dielectric and acoustic properties of breast tissues, respectively. For compactness, the target values, i.e. dielectric and acoustic properties, are shown at only two frequencies, i.e. $2.5 \mathrm{GHz}$ and $7 \mathrm{MHz}$, as reference for MWI and US applications, respectively.

Starting from two different agar-based recipes, a good match with the properties listed on Tables 1 and 2 was pursued by adding fat, $\mathrm{NaCl}$ and sugar.

Table 1. Reference values for dielectric properties in breast tissues at $2.5 \mathrm{GHz}$ [10], [11].

\begin{tabular}{|l|c|c|}
\hline & $\begin{array}{c}\text { Relative } \\
\text { permittivity }\end{array}$ & $\begin{array}{c}\text { Conductivity } \\
(\mathbf{S} / \boldsymbol{m})\end{array}$ \\
\hline Skin & $38.007^{*}$ & $1.464 *$ \\
\hline $\begin{array}{l}\text { Subcutaneous } \\
\text { Fat } \\
\text { tissue }\end{array}$ & $5.1467^{*}$ & $0.13704 *$ \\
\hline Tumor & $35.7-65.3 \ddagger$ & $1.52-2.37 \ddagger$ \\
\hline Pectoral Muscle & $52.729^{*}$ & $1.89 \ddagger$ \\
\hline
\end{tabular}

Lazebnik et al., 2007, *Andreuccetti et al., 1997.

Table 2. Reference values for acoustic properties in breast tissues [12], [13], [14], [15].

\begin{tabular}{|l|c|c|}
\hline & $\begin{array}{c}\text { Speed of } \\
\text { sound }\left(\mathbf{m s}^{-1}\right)\end{array}$ & $\begin{array}{c}\text { Attenuation } \\
\text { coefficient } \\
\left(\boldsymbol{d B}_{\text {cm}^{-1}} \mathbf{M H z}^{-1}\right)\end{array}$ \\
\hline Skin & $1537 \ddagger$ & $1.84 \pm 0.44$ at $7 \mathrm{MHz} \dagger$ \\
\hline $\begin{array}{l}\text { Subcutaneous } \\
\text { Fat }\end{array}$ & $1479 \pm 32^{*}$ & $0.6 \pm 0.1$ at $7 \mathrm{MHz} \S$ \\
\hline $\begin{array}{l}\text { Fibroglandular } \\
\text { tissue }\end{array}$ & $1553 \pm 35^{*}$ & $2.0 \pm 0.7$ at $7 \mathrm{MHz} \S$ \\
\hline Tumor & $1550 \pm 35^{*}$ & $1.0 \pm 0.2$ at $7 \mathrm{MHz} \S$ \\
\hline
\end{tabular}

$\$$ Yongchen et al., 1986, * Scherzinger et al., 1988, ${ }^{\dagger}$ Dussik et al., 1958, ${ }^{\S}$ D'Astous and Foster, 1986.

\subsection{IEC TMM-based recipes}

The International Electrotechnical Commission (IEC) TMM - whose ingredients and percentages by weight are given in Table 3 [16] - proved to have ideal acoustic properties, good $\mathrm{T} 1$ and $\mathrm{T} 2$ relaxation times, as well as the Hounsfield Unit [17] (ref. Table 4) to be adapted with small recipe variation to mimic different breast tissues.

Table 3. Weight composition of the IEC TMM [16].

\begin{tabular}{|c|c|}
\hline Components & $\begin{array}{c}\text { Weight composition } \\
\text { (\%) }\end{array}$ \\
\hline Glycerol & $11.21 \%$ \\
\hline Benzalkoniumchloride & $0.46 \%$ \\
\hline Si-C powder 400 grain & $0.53 \%$ \\
\hline Al2O3-powder $3.0 \mu \mathrm{m}$ & $0.94 \%$ \\
\hline Al203-powder $0.3 \mu \mathrm{m}$ & $0.88 \%$ \\
\hline Agar & $3 \%$ \\
\hline Deionized water & $82.97 \%$ \\
\hline
\end{tabular}

Table 4. IEC TMM properties [17].

\begin{tabular}{|c|c|}
\hline Attenuation coefficient & $0.52 \pm 0.3 \mathrm{~dB} \mathrm{~cm}^{-1} \mathrm{MHz}^{-1}$ \\
\hline Speed of sound & $1549 \pm 5 \mathrm{~m} \mathrm{~s}^{-1}$ \\
\hline $\boldsymbol{T 1}$ & $1504 \pm 10 \mathrm{~ms}$ \\
\hline $\boldsymbol{T} \boldsymbol{H U}$ & $40 \pm 0.4 \mathrm{~ms}$ \\
\hline $\boldsymbol{H U}$ & $58.6 \pm 7.3$ \\
\hline
\end{tabular}

The IEC TMM has high water content. But the addition of a Fat component ( $80 \%$ olive oil and $20 \%$ surfactant) was then considered to obtain different values of permittivity. This proportion of oil and surfactant is advantageous in terms of homogeneity and long stability of the mixture. These properties are important when aggregating components need to be added to create cross-link. On the other hand, different concentrations of $\mathrm{NaCl}$ were added to the IEC TMM to study the effect on relative permittivity but mainly on conductivity.

\subsection{Basic TMM-based recipes}

A basic mixture was considered including just deionized water $(97 \%)$ with enough agar to gel the mixture (3\%). To this mixture ingredients such as $\mathrm{NaCl}$, sugar and Fat component were then added to assess the effects on the dielectric properties.

\subsection{Measurement setup}

The setup for broadband measurement of dielectric properties of the TMM samples consisted of a R\&S®ZVB8 Vector Network Analyser (Rhode \& Schwartz, Munich, Germany, operating frequency band $300 \mathrm{kHz}-8 \mathrm{GHz}$ ), an open-ended coaxial probe, and a coaxial cable used to connect the probe to the VNA. The probe was constructed from standard $6.3 \mathrm{~mm}$ diameter $50 \Omega$ Teflon-filled semirigid coaxial cable (RG401) whose inner conductor had a 
diameter of $1.63 \mathrm{~mm}$, while the external shield had a mean diameter of $5.28 \mathrm{~mm}$. The measurement was carried out following the method described in [18]. Four reference loads were first used for calibration: open circuit, short circuit and two reference liquids, whose dielectric properties are well-known. As for the short circuit condition, this was achieved by pressing copper foil against the end of the probe. The reference liquids were deionized water and methanol which are stable and highly documented in the literature. The complex reflection coefficient S11 was then measured for the four reference loads and for the TMM sample. After every measurement, the probe was cleaned by immersion into an isopropylalcohol solution. The measured reflection coefficients were processed by the in-house developed MATLAB program described in [19].

The acoustic characterization was carried out using a Scanning Acoustic Macroscope (SAMa) system. The system included a 1-20 MHz pulser receiver (Model 5052PR, Panametrics, USA), an 8-bit $100 \mathrm{MHz}$ general purpose analog-to-digital input/output PC board (PCI 5144, National Instruments, USA) and a LabView interface (National Instruments, USA). The SAMa was operated in pulse-echo configuration, which involves a single transducer acting as both a transmitter and a receiver. The employed broadband immersion transducer had frequencies centred at $7.5 \mathrm{MHz}$, with frequency range 5.15 MHz-9.44 MHz, focal point $9.54 \mathrm{~cm}$ and crystal diameter $12.7 \mathrm{~mm}$. the frequency range matches with the operating frequency range in breast ultrasound $(5-13 \mathrm{MHz})$. The driving voltage of the transducer was set to $100 \mathrm{~V}$ to minimize non-linearity effects. The transducer was immersed in a tank containing deionized water as reference medium, being careful that air bubbles didn't adhere to the transducer face and cause field disturbance. A glass plate was put at the bottom of the tank, acting as a plane reflector. The face of the transducer was positioned parallel to the bottom of the water tank, at a distance of $9.54 \mathrm{~cm}$ from the glass so that the focus was on its surface.

\section{Results and Discussion}

As expected, the addition of the Fat component to the IEC TMM decreases both permittivity and conductivity of the mixture in a controlled way (Figure 1). The behavior of the mixture for different amount of the Fat component suggests that the relative permittivity can be modulated to meet the target values of breast tissues listed on Table 1. However, the conductivity remains significantly lower than typical values in breast tissues. In an attempt of modifying the conductivity profile of the IEC TMM, different amounts of $\mathrm{NaCl}$ were added to the mixture including $10 \%$ of Fat component. $\mathrm{NaCl}$ plays a powerful effect on the dielectric properties of the IEC TMM as it lowers both permittivity and conductivity (Figure 2).

$\mathrm{NaCl}$, sugar and Fat were added in different percentages to the Basic TMM mixture. As shown in Figure 3, increasing the percentage of $\mathrm{NaCl}$ resulted in lower permittivity and higher conductivity. The same happens for sugar. However, the rate of decreasing of permittivity and increasing of conductivity was lower for sugar. This means that a higher percentage of sugar was required to have the same effect as $\mathrm{NaCl}$. For this reason, in the final goal of developing breast TMMs, sugar can be used for a finer tuning of permittivity and conductivity values, while $\mathrm{NaCl}$ could be used for a coarse correction.

The results in Fig. 1-3 show the suitability of some recipes to mimic breast tissues in the frequency range under investigation. Table 5 summarizes three recipes based on the TMM techniques above discussed that can simulate the behavior of fibroglandular, tumor and pectoral muscle tissues in terms of dielectric and acoustic properties. The comparison with referenced data shows that good agreement was found in terms of dielectric properties. Regarding the acoustic characterization, good agreement was found in terms of speed of sound in all three mixtures. However, measured values of attenuation are significantly lower than reference values.

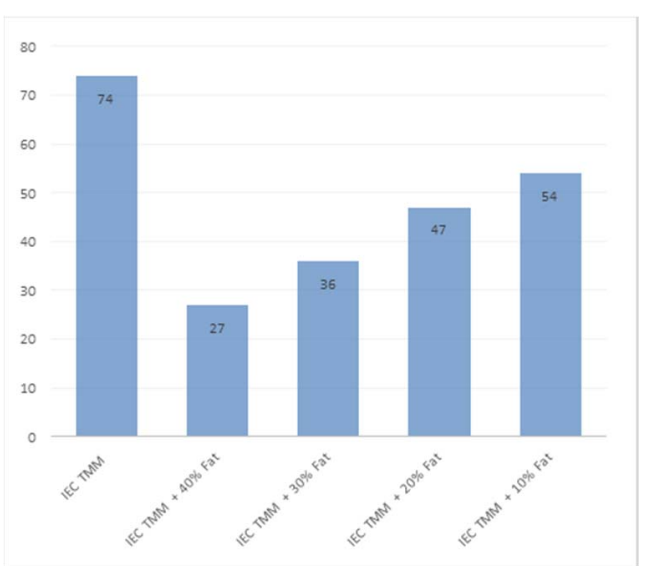

(a)

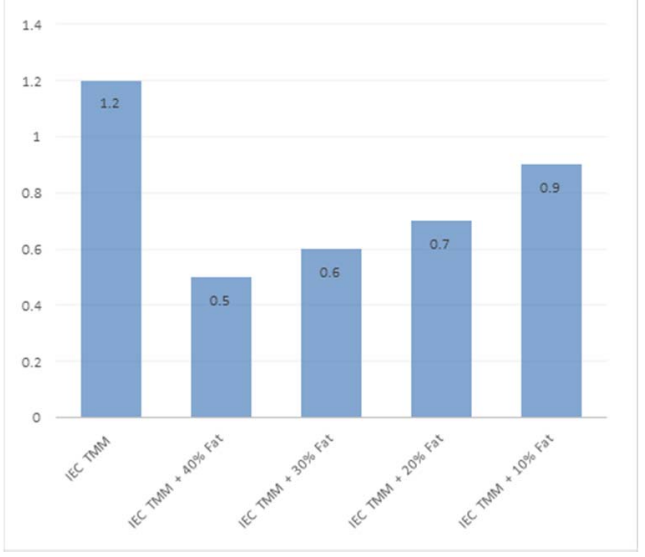

(b)

Figure 1. Investigation on the effects of Fat on the dielectric properties at $2.5 \mathrm{GHz}$ of the IEC TMM. (a) relative permittivity; (b) conductivity $(\mathrm{S} / \mathrm{m})$ 


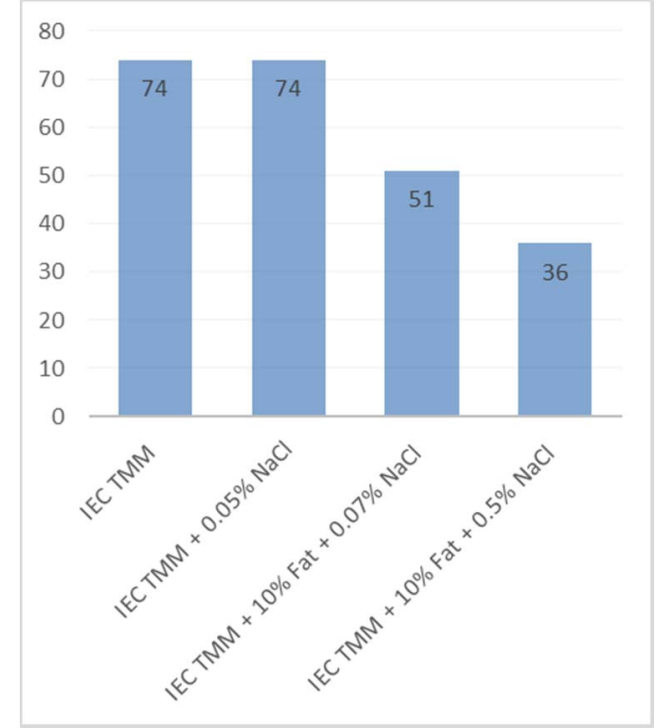

(a)

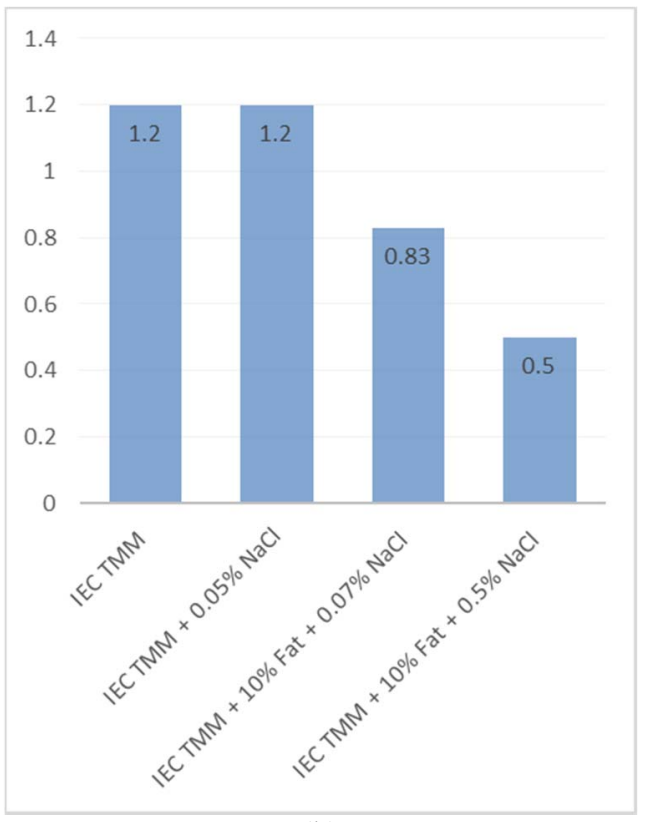

(b)

Figure 2. Investigation on the effects of $\mathrm{NaCl}$ on the dielectric properties at $2.5 \mathrm{GHz}$ of the IEC TMM. (a) relative permittivity; (b) conductivity $(\mathrm{S} / \mathrm{m})$

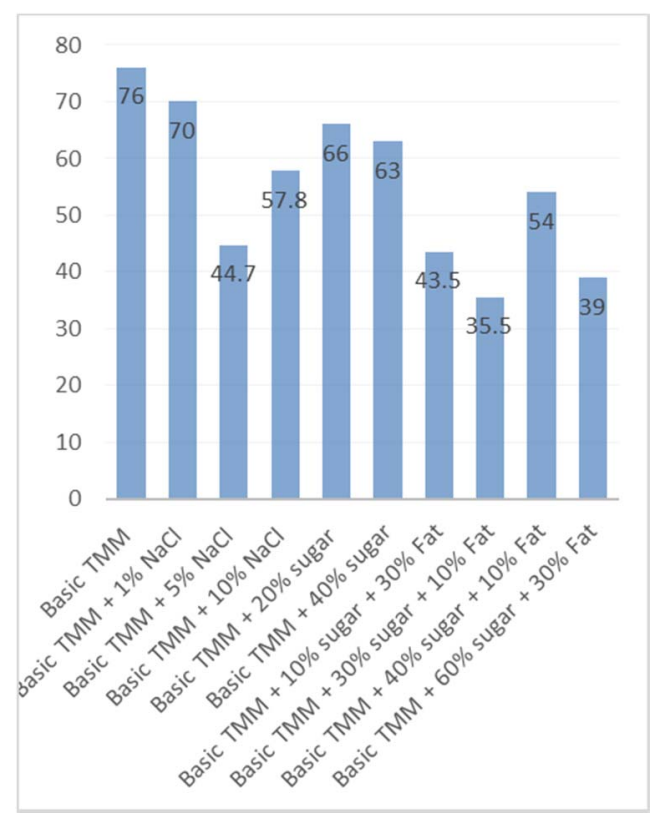

(a)

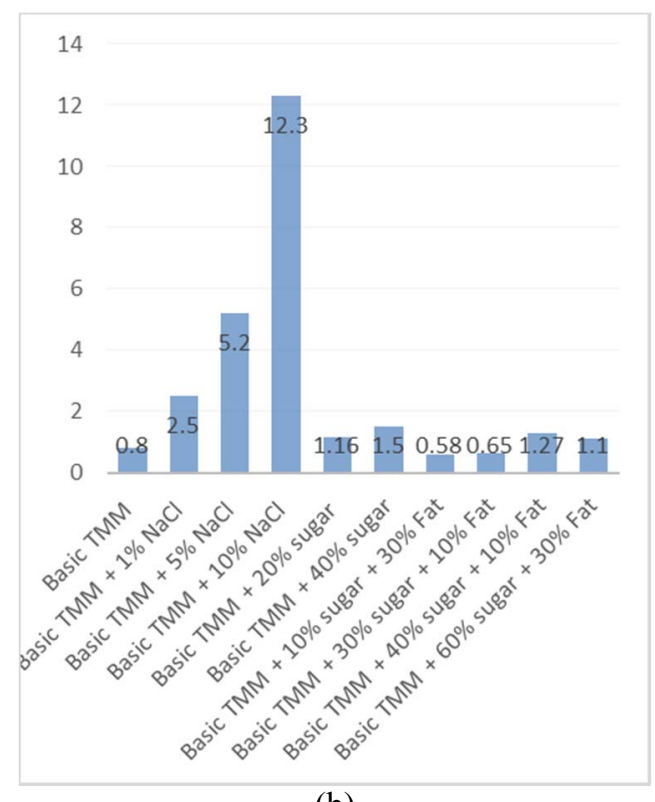

(b)

Figure 3. Investigation on the effects of $\mathrm{NaCl}$ and sugar on the dielectric properties at $2.5 \mathrm{GHz}$ of the Basic TMM. (a) relative permittivity; (b) conductivity $(\mathrm{S} / \mathrm{m})$ 
Table 5. Dielectric and acoustic characterization of final set of recipes for breast tissues.

\begin{tabular}{|c|c|c|c|}
\hline & $\begin{array}{c}\text { Fibroglandular } \\
\text { tissue }\end{array}$ & Tumor & $\begin{array}{c}\text { Pectoral } \\
\text { muscle }\end{array}$ \\
\hline Mixture & $\begin{array}{l}\text { IEC TMM } \\
+20 \% \text { Fat }\end{array}$ & $\begin{array}{c}\text { Basic TMM } \\
+20 \% \text { sugar } \\
+1 \% \mathrm{NaCl}\end{array}$ & $\begin{array}{c}\text { Basic TMM } \\
+40 \% \text { sugar } \\
+10 \% \text { Fat }\end{array}$ \\
\hline $\begin{array}{c}\text { Reference } \\
\mathcal{E}_{\mathrm{r}} \text { at } 2.5 \\
\mathbf{G H z}\end{array}$ & 44 & 66 & 53 \\
\hline $\begin{array}{c}\text { Measured } \\
\varepsilon_{\mathrm{r}} \text { at } 2.5 \\
\mathbf{G H z}\end{array}$ & 47 & 68 & 54 \\
\hline $\begin{array}{c}\text { Reference } \\
\sigma \text { at } 2.5 \\
\text { GHz }\end{array}$ & 0.8 & 2.2 & 1.74 \\
\hline $\begin{array}{c}\text { Measured } \\
\sigma \text { at } 2.5 \\
\text { GHz }\end{array}$ & 0.7 & 2.35 & 1.27 \\
\hline $\begin{array}{c}\text { Reference } \\
\text { Speed of } \\
\text { sound } \\
\left(\mathrm{ms}^{-1}\right) \text { at } 7.5 \\
\mathrm{MHz}\end{array}$ & $1553 \pm 35$ & $1550 \pm 35$ & $1568 \pm 5$ \\
\hline $\begin{array}{c}\text { Measured } \\
\text { Speed of } \\
\text { sound } \\
\left(\mathrm{ms}^{-1}\right) \text { at } 7.5 \\
\text { MHz }\end{array}$ & $1532.41 \pm 3.74$ & $1572.88 \pm 1.16$ & $1576.82 \pm 2.57$ \\
\hline $\begin{array}{c}\text { Reference } \\
\text { Attenuation } \\
\text { coefficient } \\
\text { at } 7 \mathrm{MHz} \\
\left(\mathrm{dB} \mathrm{cm}^{-1}\right. \\
\left.\mathbf{M H z}^{-1}\right)\end{array}$ & $2.0 \pm 0.7$ & $1.0 \pm 0.2$ & 0.8 \\
\hline $\begin{array}{c}\text { Measured } \\
\text { Attenuation } \\
\text { coefficient } \\
\text { at } 7 \mathrm{MHz} \\
\left(\mathrm{dB} \mathrm{cm}^{-1}\right. \\
\left.\mathrm{MHz}^{-1}\right)\end{array}$ & 0.7265 & 0.0941 & 0.3 \\
\hline
\end{tabular}

\section{Conclusions}

Two TMM recipes have been investigated in terms of dielectric and acoustic properties with the aim of tailoring suitable synthetic materials that mimic breast tissues in microwave and US imaging modality. Although, preliminary results show a good match between reference and measured permittivity, electrical conductivity and speed of sound, further recipe adjustment is required to meet attenuation coefficient specifications.

\section{Acknowledgements}

This paper has been supported by COST Action TD1301, MiMed, and COST Action BM1309, EMF-MED. This project has received funding from the European Union's Horizon 2020 research and innovation programme under the Marie Skłodowska-Curie grant agreement No 713690 and from the European Research Council under the
European Union's Horizon 2020 Programme/ERC PoC Grant REALTA n. 754308.

\section{References}

[1] http://www.who.int/cancer/en/

[2] http://www.cancer.org

[3] Li D., Meaney P.M., Tosteson T.D., Jiang S., Kerner T.E., McBride T.O., Pogue B.W., Hartov A., Paulsen K.D., "Comparisons of three alternative breast modalities in a common phantom imaging experiment", Medical Physics, vol. 30, no. 8, 2003.

[4] Lazebnik M., Madsen E.L., Frank G.R., Hagness, S.C., "Tissue-mimicking phantom materials for narrowband and ultrawideband microwave applications," Physics in Medicine and Biology, vol. 50, no. 18, pp. 4245-4258, 2005.

[5] Sill J.M., Fear E.C., "Tissue sensing adaptive radar for breast cancer detection - experimental investigation of simple tumor models", IEEE Transactions on Microwave Theory and Techniques, vol. 53, no. 11, pp. 3312-3319, 2005.

[6] Winters D.W., Shea J.D., Madsen E.L., Frank G.R., Van Veen B.D., Hagness S.C., "Estimating the breast surface using UWB microwave monostatic backscatter measurements", IEEE Transactions on Biomedical Engineering, vol. 55, no. 1, 247-256, 2008.

[7] Klemm M., Leendertz J.A., Gibbins D., Craddock I.J., Preece A., Benjamin R., "Microwave radar-based breast cancer detection: Imaging in inhomogeneous breast phantoms", IEEE Antennas and Wireless Propagation Letters, vol. 8, pp. 1349-1352, 2009.

[8] Mashal A., Gao F., Hagness S., "Heterogeneous anthropomorphic phantoms with realistic dielectric properties for microwave breast imaging experiments", Microw. Opt. Technol. Lett., vol. 53, no. 8, pp. 1896-1902, 2011.

[9] Burfeindt M., Colgan T., Mays R., Shea J., Behdad N., Van Veen B., Hagness S., "Mri-derived 3d-printed breast phantom for microwave breast imaging validation," IEEE Antennas Wirel Propag Lett., vol. 11, pp. 1610-1613, 2012.

[10] Lazebnik M., Okoniewski M., Booske J.H., Hagness S.C., "Highly Accurate Debye Models for Normal and Malignant Breast Tissue Dielectric Properties at Microwave Frequencies", IEEE, vol. 17, n. 12, pp. 822-824, December 2007.

[11] Andreuccetti D., Fossi R., Petrucci C., "An Internet resource for the calculation of the dielectric properties of body tissues in the frequency range $10 \mathrm{~Hz}-100$ GHz", Website at http://niremf.ifac.cnr.it/tissprop/. IFAC-CNR, Florence (Italy), 1997. Based on data published by C.Gabriel et al. in 1996.

[12] Yongchen S., Yanwu D., Jia T., Zhensheng T., "Ultrasonic Propagation Parameters in Human Tissues", IEEE, Ultrasonic Symp Proc, 905-908, 1985. 
[13] Scherzinger A.L., Belgam R.A., Carson P.L., Meyer C.R., Sutherland J.V., Bookstein F.L., Silver T.M., "Assessment of ultrasonic computed-tomography in symptomatic breast patients by discriminantanalysis", Ultrasound Med Biol, vol. 15, pp. 21-8, 1988.

[14] Dussik K.T., Fritch D.J, Kyriazidou M., Sear R.S, "Measurements of articular tissue with ultrasound", AM J Phys Med, vol. 37, pp. 160-165, 1958.

[15] D'Astous F.T., Foster F.S., "Frequency-dependence of ultrasound attenuation and backscatter in breasttissue", Ultrasound Med Biol, vol. 12, pp. 795-808, 1986.

[16] Teirlinck C.J.P.M., Bezemer R.A., Kollmann C., Lubbers J., Hoskins P.R., Ramnarine K.V., Fish P., Fredfeldt K.E., Schaarschmidt U.G., "Development of an example flow test object and comparison of five of these test objects, constructed in various laboratories", Ultrasonics, vol. 36, pp. 653-660, 1998.

[17] King D.M., Fagan A.J., Moran C.M., Browne J.E., "Comparative imaging study in ultrasound, MRI, CT, and DSA, using a multimodality renal artery phantom", Medical Physics, vol. 38, No.2, p 570, February 2011.

[18] Marsland T.P., Evans S., "Dielectric measurements with an open-ended coaxial probe", Microwaves Antennas and Propagation, vol. 134, pp. 341-349, August 1987.

[19] L. Farina, G. Ruvio, R. Pinto, L. Vannucci, M. Cavagnaro, and V. Lopresto, "Development of a portable setup suitable for in vivo measurement of the dielectric properties of biological tissues", 11th European Conference on Antennas and Propagation (EUCAP), 2017. 